\title{
Article
}

\section{Can the use of Proprioceptive Knee Braces have Implications in the Management of Osteoarthritic Knees: An exploratory study?}

Kwaees, Tariq A, Richards, James, Rawlinson, Gillian, Charalambous, Charalambos Panayiotou and Chohan, Ambreen

Available at http://clok.uclan.ac.uk/23640/

Kwaees, Tariq A, Richards, James ORCID: 0000-0002-4004-3115, Rawlinson, Gillian, Charalambous, Charalambos Panayiotou and Chohan, Ambreen ORCID: 0000-0003-0544-7832 (2019) Can the use of Proprioceptive Knee Braces have Implications in the Management of Osteoarthritic Knees: An exploratory study? Prosthetics and Orthotics International, 43 (2). pp. 140147. ISSN 0309-3646

It is advisable to refer to the publisher's version if you intend to cite from the work. http://dx.doi.org/10.1177/0309364618796852

For more information about UCLan's research in this area go to http://www.uclan.ac.uk/researchgroups/ and search for <name of research Group>.

For information about Research generally at UCLan please go to http://www.uclan.ac.uk/research/

All outputs in CLoK are protected by Intellectual Property Rights law, including Copyright law. Copyright, IPR and Moral Rights for the works on this site are retained by the individual authors and/or other copyright owners. Terms and conditions for use of this material are defined in the policies page. 
Can the use of Proprioceptive Knee Braces have Implications in the Management of Osteoarthritic Knees: An exploratory study?

\author{
Ambreen Chohan ${ }^{1}$ \\ Tariq Adam Kwaees ${ }^{1}$ \\ Gill Rawlinson ${ }^{1}$ \\ Charalambos Panayiotou Charalambous $2,3,4$ \\ Jim Richards ${ }^{1}$
}

${ }^{1}$ Allied Health Research Unit, University of Central Lancashire, Preston, Lancashire, PR1 2HE, UK.

${ }^{2}$ School of Medicine and Dentistry, University of Central Lancashire, Fylde Road, Preston, Lancashire, PR1 2HE, UK.

${ }^{3}$ Department of Orthopaedics, Blackpool Victoria Hospital, Whinney Heys Road Blackpool, Lancashire, FY3 8NR, UK

${ }^{4}$ Institute of Inflammation and Repair, Faculty of Medical and Human Sciences, University of Manchester, Oxford Road, Manchester, M13 9PL, UK. 


\section{Declaration of conflicting interests}

The authors would like to thank DJO global for supplying the proprioceptive knee braces. The authors received no financial or other reward to undertake this research and there is no conflict of interest in relation to the research. 


\section{Abstract}

Background: Use of proprioceptive knee braces to control symptomology by altering neuromuscular control mechanisms has been shown in patellofemoral pain. Though their potential in patients with knee osteoarthritis $(O A)$ is vast, little research has examined their efficacy. Methods: Thirteen healthy participants were asked to perform a $10 \mathrm{~cm}$ stepdown task with and without a Proprioceptive Brace. Data was collected using a 10-camera Qualisys system. Individuals with OA completed the Knee Osteoarthritis Outcome Score (KOOS) pre- and post 4-week intervention. Results: During stepdown reductions in knee maximum internal rotation, transverse range of movement, transverse plane angular velocity and maximum internal rotation angular velocity was seen. Ankle plantar flexion and inversion angular velocity decreased while inversion and maximum supination angular velocity increased. Improvements in KOOS were noted across all parameters with brace use. Conclusions: Positive changes in kinematic variables in multiple planes can be achieved with proprioceptive bracing alongside improved patient outcome. These changes occur at the knee but analysis of other weight bearing joints should not be overlooked in future studies. This study supports the concept of neuromuscular reinforcement and re-education through proprioceptive bracing and its application in the management in knee OA. (191 words)

Clinical relevance: Proprioception can alter symptoms and biomechanics embraced and adjacent lower limb joints. The results of this study highlights the potential uses of non-mechanical bracing in the treatment of $O A$ and other potential to bridge the OA treatment gap. Further large-scale research is needed to match disease subset to brace type. Word count: $\mathbf{5 0}$ words. 


\section{Background and Objectives}

Knee Osteoarthritis (OA) is incurable and results in progressive restriction of daily activity [1, 2]. The number of patients who fall within the OA treatment gap, defined as patients who are unsuitable for replacement surgery due to age/quality of life and therefore facing a prolonged period of failing conservative management [3], is projected to rise in line with demographics. The consideration of interventions that may bridge this gap are therefore of significant clinical importance.

Current clinical management of knee $O A$ is aimed at preventing disability and treatment options may be divided into three overlapping phases. Initially, the patient is encouraged to manage through weight loss, exercise and physical/occupational therapy, the latter of which includes orthotics in the form of knee braces and insoles [4-6]. The second phase consists of systemic or intra-articular pharmacological management, including steroids, various analgesics and viscosupplementation [7,8]. The final phase consists of surgery, which may include arthroscopic procedures, arthrodesis, osteotomy and arthroplasty [9-11]. These options are tailored to the individual patient and to the stage of disease at presentation. The effectiveness of the different phases has been subject to significant deliberation within the medical community and many healthcare organisations in various countries have attempted to streamline and simplify the options available for clinical use (Table 1). The concept of proprioceptive bracing does not currently feature in these guidelines, and knee braces typically comprise of a combination of metallic, foam, elastic and non-elastic material. However, such braces are varied in their design, function, intended use and clinical outcomes also vary $[12,16]$.

Knee braces have recently been classified into two broad groups; mechanical and nonmechanical $[14,16,17]$. Mechanical braces aim to provide support or control in one or more planes of movement, forcibly correcting or supporting altered anatomy through a three point fixation system [18-21]. This has been shown to reduce the knee adduction moment during gait by reducing the moment arm and increasing the compartmental intercondylar distance, and subsequently reducing the force traveling through the medial compartment of the knee joint $[16,18,20,21]$. However, knee osteoarthritis is panarticular and therefore adversely affects proprioception and neuromuscular control [22-25], which is reinforced by studies which have shown that proprioceptive reinforcement can improve symptomology and abnormalities in knee function [18,22,27-31]. Non-mechanical braces or proprioceptive bracing attempt to reinforce this proprioceptive feedback resulting in better control and improved symptomology. 
Factors likely to influence patient behaviour are the wearability of a brace, its efficacy and cost [32]. It is known for example that the mechanical advantage in correct alignment increases with the length of the brace, but at the same time patient adherence generally diminishes. Despite the documented improvements in Patient Reported Outcome Measures (PROMS), there is an unwillingness amongst patients to wear knee braces for prolonged periods [32]. Brouwer et al [33] found that only $58 \%$ of patients were wearing a provided brace after 1 year, and of those that stopped using the brace, $64 \%$ did so within the first three months. Key reasons for this lack of adherence to intervention were skin irritation, bad fit and lack of improvements in symptoms [32]. The literature predominantly considers at the short term effects of such braces $[18,21,34]$ and although some studies have found longer term improvements in gait and PROMS at 6 months [16], the period of time required for brace acclimatisation is unknown and it is difficult to gauge the optimum period of wear to assess changes in gait and neuromuscular adaptations [16,35]. Factors playing a key role in the wearability of a brace are not fully understood. However, these may include the perceived social stigma of wearing a brace, bulkiness, practicality and or discomfort $[13,14,36]$. This could be particularly pertinent for mechanical knee braces where employing a three-point fixation system, which invariably leads to increase pressure on the anatomical structures to achieve an offloading effect [37]. Kutzner et al. reported that an eight degree correction may be the upper limit of tolerability for comfort [37], although more research is needed to identify optimum angle to load ratio $[20,33,37]$, which may also be affected by the coronal plane knee stiffness.

A new generation of braces is becoming available in response to some of these issues. One such brace is the OA Reaction (DJO inc.), which includes silicone webbing, fabric and minimal metallic hinge components. Such braces may have the potential to provide proprioceptive feedback to improve knee stability [38] and improve usability, adherence and quality of life and may be better suited to younger, more active patients within the treatment gap.

This study aimed to investigate the efficacy and effectiveness of the OA Reaction proprioceptive knee brace on kinematics during a slow step down in healthy participants and individuals with medial compartment knee OA. The effects of the brace on patient reported outcomes in individuals with OA before and after four weeks of wear were assessed using the Knee injury and Osteoarthritis Outcome Score (KOOS). 


\section{Methods}

\section{Participants}

Thirteen healthy participants (age: $42 \pm 12$ years; height: $178 \pm 16.5 \mathrm{~cm}$; weight: $81 \pm 17 \mathrm{~kg}$ ), were recruited from university staff/student population, with no history of lower limb OA, trauma or surgery. In addition, 3 participants with medial compartment knee OA grade 2-3 on the Kellgren-Lawrence scale, (age: $48 \pm 9.2$ years), with no history of major trauma or surgery to the lower limbs and were able to walk without the use of an aid were self-volunteered for the study. All data collection conformed to the Declaration of Helsinki and volunteers gave written informed consent prior to participation. The study was approved by the University's Ethics Committee (STEMH 235 \& 356).

\section{Procedure}

Passive retro-reflective markers were placed on the lower limbs and pelvis using the Calibrated Anatomical System Technique (CAST) to allow for segmental kinematics to be tracked in 6-degrees of freedom (Figure 1). Markers were positioned on the anterior superior iliac spine, posterior superior iliac spine, greater trochanter, medial and lateral femoral epicondyle, medial and lateral malleoli, the head of the $1^{\text {st }}$ metatarsal, the head of the $5^{\text {th }}$ metatarsal, the dorsum of the foot and the calcaneus or equivalent placement over these landmarks on the shoe. Additionally clusters of four non-collinear markers were attached to the body segments of the shank and thigh. Kinematic data were collected using a ten camera infra-red Oqus motion analysis system (Qualisys medical AB, Gothenberg, SE) at $100 \mathrm{~Hz}$. All participants were asked to perform a step down from a $10 \mathrm{~cm}$ step with and without the proprioceptive brace (OA Reaction, DJO, USA). Whilst it has been shown that $20 \mathrm{~cm}$ is considered a standard step height to mimic daily scenarios, it has been show to create a significant challenge to some individuals with knee pain [38]. Therefore a $10 \mathrm{~cm}$ height was considered to be a sufficient challenge to individuals with knee OA, without overloading the knee joint $[39,40]$. Five repetitions for each condition were performed in a randomised order. The brace was applied in accordance with the manufacturer's instructions on the dominant or affected knee (for OA cases). Anatomical frames were defined by landmarks positioned at the medial and lateral borders of the joint, from these right handed segment co-ordinate systems were defined. The kinematics were calculated based on the cardan sequence of $X Y Z$.

In addition to the step down tasks, the individuals with OA were asked to complete the Knee Osteoarthritis Outcome Score (KOOS). This is a patient reported outcome measure, that was developed to assess patient opinion on their associated knee problems relating specifically to symptoms, pain, activities of daily living, sport and recreational activity, and overall quality of 
life. For the intervention participants with OA were given the under sleeve and brace to use as per manufacturer guidance and subjective feedback and PROMS were followed up at four weeks.

\section{Data Analysis}

Raw kinematic data were exported to Visual3D (C-Motion Inc., USA). Kinematic data were filtered using fourth order Butterworth filters with cut off frequencies of 6 and $25 \mathrm{~Hz}$, respectively. Knee, hip and ankle angle data was exported and paired t-tests were performed on maximum, minimum and range values using SPSS v24 (IBM,NY, USA).

The KOOS data from each individual with OA were considered in relation to a 10 point change which has been suggested as showing a clinically important change [41]. In addition, following successful completion of the step down task, the participants with and without OA were asked to give their subjective opinion regarding the wearability of the brace and perceived in comfort and stability.

\section{RESULTS}

\section{Healthy Participants Kinematics}

In the healthy individuals the maximum knee external rotation was reduced by a mean of $1.7^{\circ}$ when wearing the brace $(p=0.005)$. Significant changes were also seen in the transverse plane knee range of movement ( $p=0.001)$, with a reduction from 5.4 to $4.2^{\circ}$ when wearing the brace. A significant change in the range of angular velocities at the knee in the transverse plane was seen $(p=0.001)$ with a reduction of $6.72 \%$ when wearing the brace, with corresponding reductions in both maximum internal and external rotation angular velocities $3.6 \% \mathrm{~s}(p=0.037)$ and $3.3 \%(p=0.006)$ respectively, table 3 . No changes were seen in hip angles in any plane (table 2). However, maximum internal rotation angular velocity at the hip was significantly reduced by $2.65^{\circ} / \mathrm{s}(p=0.025)$ (table 3 ). Significant changes were seen in the ankle joint coronal plane, with a decrease in ankle inversion of $1.1^{\circ}$ when wearing the brace $(p=0.049)$. Similarly, inversion angular velocity decreased significantly by $2.5 \mathrm{deg} / \mathrm{s}$ when wearing the brace $(p=0.024)$. Statistically significant changes in the transverse angular velocities were noted with an increase of $6.3 \mathrm{deg} / \mathrm{s}$ in maximum supination angular velocity when wearing the brace $(p=0.010)$. 


\section{Subjective Feedback \& Patient Reported Outcome Measures}

Most of the healthy participants (11 of the 13 healthy participants), and all three participants with OA gave positive subjective feedback regarding the design and wearability of the brace. Positive comments included "better fitting for clothing", "better stability for sport and muscle building", "easier control for step down" and "snug and comfortable". Negative comments from participants with OA included feedback on sensation of pressure over the lateral aspect of the knee joint applied by the brace.

All participants with OA demonstrated improvements in KOOS post intervention. Improvements in KOOS occurred across all tested parameters with brace use and were on average an improvement of $85.5 \%$ in pain, $57.6 \%$ in symptomology, $81.2 \%$ in activities of daily living, 255.2\% for sports and recreation and a $127.7 \%$ in Quality of Life (table 4). Each individual with OA reported an improvement of at least 17.9 points (25\% improvement) in Pain, Symptoms, Activities of Daily Living and Sport/Recreation, well above the 10 point threshold considered as a clinically important change [41]. For Quality of Life one participant of the three with $\mathrm{OA}$ saw an improvement below this threshold of 6.2 point in, however the remaining participants saw a 25 and 43.8 point improvement respectively.

\section{DISCUSSION}

\section{Kinematics}

The use of range of motion in of the knee in the transverse plane [38] and angular velocity [42] have been suggested as a measurement of neuromuscular control. Whereby a reduction in total range of movement when an identical task is performed, may allude to better control. From the results of this study, it is possible to confirm that subtle changes in lower limb biomechanics can occur when using a proprioceptive knee brace. These changes appear to improve the neuromuscular control at the knee, and change control strategies in proximal and distal joints to the brace in healthy individuals.

Whilst gait is often the task of choice for analysis of movement following a knee brace intervention, activities of daily living e.g. stair descent may lead to pain in individuals with conditions such as Knee OA. A better understanding of such activities could help lead to better solutions, affording further adherence to intervention. Changes in stability were seen in the step down results of this study, including reductions in maximum knee internal rotation, transverse range of movement and transverse angular velocity with use of the brace. The results confirm findings of previous research which examined a proprioceptive device and found significant changes in transverse plane kinematics $[17,38]$. 
Previous studies have noted significant changes in sagittal plane kinematics at the knee [43] but few changes in other planes were reported during step negotiation with the use of proprioceptive knee bracing. The present study showed no changes in sagittal plane kinematics at the hip, knee or ankle. However, in healthy participants a significant reduction in maximum hip internal rotation angular velocity, maximum ankle inversion angular velocity; with a corresponding decrease in ankle inversion and maximum supination angular velocity.

The results of this study highlight the importance of wearability and effective implementation of a proprioceptive brace. Overall participants with OA had a favourable opinion of the brace design; with the low profile and wearability of the brace being defined as key factors in adherence to the intervention. It was also found that participants who had previously utilised bracing were more likely have a favourable opinion regarding comfort but were more likely to comment on the restriction in movement at the knee joint and the assisted extension produced by the brace. It is known that continued use of knee braces can be low amongst individuals with $\mathrm{OA}$ and previous publications have highlighted key reasons for this including skin irritation, bad fit and lack of improvements in symptomology [32]. Other key factors relating to braces include perceived social stigma of the brace, bulkiness, practicality and/or discomfort especially with larger braces $[13,14,36]$. During the testing phase of the present study there were some negative comments from participants with $\mathrm{OA}$ which included sensation of pressure over the lateral aspect of the knee joint applied by the hinge unit. However, this could be related to the intentional abandonment of the under sleeve which may be worn underneath the brace during data collection to allow retroreflective markers to be attached.

\section{Subjective Feedback \& PROMs}

The issue of aesthetics' to patients is arguably of great significance for bridging the OA treatment gap but that there is little data on the issue. Jones et al postulated that a discrete orthosis is more attractive to patients [36], however the current literature does not investigate this issue in detail. Current data also predominantly looks at the short term effects of bracing $[18,21,34]$ and no studies were found which investigate the period of time required for brace acclimatization, long term use rates, purchase data of over the counter or generic devices and long term self-management with orthoses among OA patients. The KOOS scores of OA participants in the present study showed significant improvements across all tested parameters. These finding agree with the current data which notes significant improvements in PROMS across multiple scoring criteria through brace use $[14,16,18,20]$. 
Current literature demonstrates a lack of consensus on the utilisation of externally applied devices for the management of OA. Most studies pertaining to knee bracing involved mechanical bracing but were highly heterogeneous in study design and methodology, making it difficult for the clinician to implement in practice. There is a paucity of studies examining proprioceptive bracing in patients with OA, however several studies have previously investigated non-mechanical bracing in patients with other disease processes. These found significant results that correlated with improvements in symptomology and limb control.

The results this study confirm that PROMs can be significantly improved with the use of proprioceptive bracing and wearability of the brace is an important factor for implementation. The results showed significant positive changes in kinematic variables in healthy individuals particularly in the transverse plane movement of the knee, which had a secondary effect on proximal and distal joints due to altered strategies of step descent. Analysis of these measures should therefore not be overlooked in future studies on patient groups. In addition, this paper further highlights the importance of multi-planar analysis in biomechanical studies, the present study has added to the growing body of evidence, which supports the concept of neuromuscular enforcement and re-education through proprioceptive bracing as an alternative to mechanical correction. Such braces hold potential in offering more patient friendly treatment modalities for the management of the knee OA treatment gap. Further research is needed to substantiate the effects of proprioceptive bracing on various clinical grades of OA in order to establish at what point in the treatment pathway this bracing technique would be most effective. 


\section{References}

1. DIEPPE, P.A. and LOHMANDER, L.S., 2005. Pathogenesis and management of pain in osteoarthritis. Lancet (London, England), 365(9463), pp. 965-973.

2. LUYTEN, F.P., DENTI, M., FILARDO, G., KON, E. And ENGEBRETSEN, L., 2012. Definition and classification of early osteoarthritis of the knee. Knee surgery, sports traumatology, arthroscopy : official journal of the ESSKA, 20(3), pp. 401-406.

3. LONDON, N.J., SMITH, J., MILLER, L.E. and BLOCK, J.E., 2013. Bridging the osteoarthritis treatment gap with the kinespring Knee Implant System: early evidence in 100 patients with 1-year minimum follow-up. Orthopedic Research and Reviews, 5, pp. 65-73.

4. BECKWEE, D., VAES, P., CNUDDE, M., SWINNEN, E. And BAUTMANS, I., 2013. Osteoarthritis of the knee: why does exercise work? A qualitative study of the literature. Ageing research reviews, 12(1), pp. 226-236.

5. NELSON, A.E., ALLEN, K.D., GOLIGHTLY, Y.M., GOODE, A.P. and JORDAN, J.M., 2014. A systematic review of recommendations and guidelines for the management of osteoarthritis: The Chronic Osteoarthritis Management Initiative of the U.S. Bone and Joint Initiative. Seminars in arthritis and rheumatism, 43(6), pp. 701-712.

6. WALLIS, J.A. and TAYLOR, N.F., 2011. Pre-operative interventions (non-surgical and non-pharmacological) for patients with hip or knee osteoarthritis awaiting joint replacement surgery--a systematic review and meta-analysis. Osteoarthritis and cartilage / OARS, Osteoarthritis Research Society, 19(12), pp. 1381-1395.

7. KON, E., FILARDO, G., DROBNIC, M., MADRY, H., JELIC, M., VAN DIJK, N. And DELLA VILLA, S., 2012. Nonsurgical management of early knee osteoarthritis. Knee surgery, sports traumatology, arthroscopy : official journal of the ESSKA, 20(3), pp. 436-449.

8. MCALINDON, T.E., BANNURU, R.R., SULLIVAN, M.C., ARDEN, N.K., BERENBAUM, F., BIERMA-ZEINSTRA, S.M., HAWKER, G.A., HENROTIN, Y., HUNTER, D.J., KAWAGUCHI, H., KWOH, K., LOHMANDER, S., RANNOU, F., ROOS, E.M. and UNDERWOOD, M., 2014b. Response to Letter to the Editor entitled "Comments on 'OARSI guidelines for the non-surgical management of knee osteoarthritis"'. Osteoarthritis and cartilage / OARS, Osteoarthritis Research Society, 22(6), pp. 890-891.

9. FRIZZIERO, L., RETA, M., RIZZUTI, F., ZIZZI, F., FRIZZIERO, A. And FACCHINI, A., 2005. Surgical approaches in osteoarthritis: role of arthroscopy. Seminars in arthritis and rheumatism, 34(6 Suppl 2), pp. 53-57.

10. KATZ, J.N., 2006. Total joint replacement in osteoarthritis. Best practice \& research.Clinical rheumatology, 20(1), pp. $145-153$.

11. RONN, K., REISCHL, N., GAUTIER, E. And JACOBI, M., 2011. Current surgical treatment of knee osteoarthritis. Arthritis, 2011, pp. 454873.

12. BEAUDREUIL, J., BENDAYA, S., FAUCHER, M., COUDEYRE, E., RIBINIK, P., REVEL, M. And RANNOU, F., 2009. Clinical practice guidelines for rest orthosis, knee sleeves, and unloading knee braces in knee osteoarthritis. Joint, bone, spine : revue du rhumatisme, 76(6), pp. 629-636.

13. DESSERY, Y., BELZILE, E.L., TURMEL, S. And CORBEIL, P., 2014. Comparison of three knee braces in the treatment of medial knee osteoarthritis. The Knee .

14. MOYER, R.F., BIRMINGHAM, T.B., BRYANT, D.M., GIFFIN, J.R., MARRIOTT, K.A. and LEITCH, K.M., 2015. Biomechanical effects of valgus knee bracing: a systematic review and meta-analysis. Osteoarthritis and cartilage $I$ OARS, Osteoarthritis Research Society, 23(2), pp. 178-188.

15. RAMSEY, D.K. and RUSSELL, M.E., 2009. Unloader braces for medial compartment knee osteoarthritis: implications on mediating progression. Sports health, 1(5), pp. 416-426.

16. RICHARDS, J.D., SANCHEZ-BALLESTER, J., JONES, R.K., DARKE, N. And LIVINGSTONE, B.N., 2005. A comparison of knee braces during walking for the treatment of osteoarthritis of the medial compartment of the knee. The Journal of bone and joint surgery. British volume, 87(7), pp. 937-939.

17. SELFE, J., THEWLIS, D., HILL, S., WHITAKER, J., SUTTON, C. And RICHARDS, J., 2011. A clinical study of the biomechanics of step descent using different treatment modalities for patellofemoral pain. Gait \& posture, 34(1), pp. 92-96.

18. GAASBEEK, R.D., GROEN, B.E., HAMPSINK, B., VAN HEERWAARDEN, R.J. and DUYSENS, J., 2007. Valgus bracing in patients with medial compartment osteoarthritis of the knee. A gait analysis study of a new brace. Gait \& posture, 26(1), pp. 3-10.

19. KOMISTEK, R.D., DENNIS, D.A., NORTHCUT, E.J., WOOD, A., PARKER, A.W. and TRAINA, S.M., 1999. An in vivo analysis of the effectiveness of the osteoarthritic knee brace during heel-strike of gait. The Journal of arthroplasty, 14(6), pp. 738-742.

20. POLLO, F.E. and JACKSON, R.W., 2006. Knee bracing for unicompartmental osteoarthritis. The Journal of the American Academy of Orthopaedic Surgeons, 14(1), pp. 5-11.

21. TORIYAMA, M., DEIE, M., SHIMADA, N., OTANI, T., SHIDAHARA, H., MAEJIMA, H., MORIYAMA, H., SHIBUYA, H., OKUHARA, A. And OCHI, M., 2011. Effects of unloading bracing on knee and hip joints for patients with medial compartment knee osteoarthritis. Clinical biomechanics (Bristol, Avon), 26(5), pp. 497-503.

22. KNOOP, J., STEULTJENS, M.P., VAN DER LEEDEN, M., VAN DER ESCH, M., THORSTENSSON, C.A., ROORDA, L.D., LEMS, W.F. and DEKKER, J., 2011. Proprioception in knee osteoarthritis: a narrative review. Osteoarthritis and cartilage / OARS, Osteoarthritis Research Society, 19(4), pp. 381-388.

23. LEPHART, S.M., PINCIVERO, D.M. and ROZZI, S.L., 1998. Proprioception of the ankle and knee. Sports medicine (Auckland, N.Z.), 25(3), pp. 149-155.

24. LUND, H., JUUL-KRISTENSEN, B., HANSEN, K., CHRISTENSEN, R., CHRISTENSEN, H., DANNESKIOLDSAMSOE, B. And BLIDDAL, H., 2008. Movement detection impaired in patients with knee osteoarthritis compared to healthy controls: a cross-sectional case-control study. Journal of Musculoskeletal \& Neuronal Interactions, 8(4), pp. 391-400. 
25. ZAZULAK, B.T., HeWeTt, T.E., REeVES, N.P., GOldBeRG, B. And CHOlEWICKI, J., 2007. Deficits in neuromuscular control of the trunk predict knee injury risk: a prospective biomechanical-epidemiologic study. The American Journal of Sports Medicine, 35(7), pp. 1123-1130.

26. BENNELL, K.L., HINMAN, R.S., METCALF, B.R., CROSSLEY, K.M., BUCHBINDER, R., SMITH, M. And MCCOLL, G., 2003. Relationship of knee joint proprioception to pain and disability in individuals with knee osteoarthritis. Journal of orthopaedic research : official publication of the Orthopaedic Research Society, 21(5), pp. 792-797.

27. COLLINS, A., BLACKBURN, J.T., OLCOTT, C., YU, B. And WEINHOLD, P., 2011a. The impact of stochastic resonance electrical stimulation and knee sleeve on impulsive loading and muscle co-contraction during gait in knee osteoarthritis. Clinical biomechanics (Bristol, Avon), 26(8), pp. 853-858.

28. DUMAN, I., TASKAYNATAN, M.A., MOHUR, H. And TAN, A.K., 2012. Assessment of the impact of proprioceptive exercises on balance and proprioception in patients with advanced knee osteoarthritis. Rheumatology international, 32(12), pp. 3793-3798.

29. JU, S.B., PARK, G.D. and KIM, S.S., 2015. Effects of proprioceptive circuit exercise on knee joint pain and muscle function in patients with knee osteoarthritis. Journal of physical therapy science, 27(8), pp. 2439-2441.

30. KAMINSKI, T.W. and PERRIN, D.H., 1996. Effect of prophylactic knee bracing on balance and joint position sense. Journal of athletic training, 31(2), pp. 131-136.

31. SANCHEZ-RAMIREZ, D.C., VAN DER LEEDEN, M., KNOL, D.L., VAN DER ESCH, M., ROORDA, L.D., VERSCHUEREN, S., VAN DIEEN, J., LEMS, W.F. and DEKKER, J., 2013. Association of postural control with muscle strength, proprioception, self-reported knee instability and activity limitations in patients with knee osteoarthritis. Journal of Rehabilitation Medicine, 45(2), pp. 192-197.

32. SQUYER, E., STAMPER, D.L., HAMILTON, D.T., SABIN, J.A. and LEOPOLD, S.S., 2013. Unloader knee braces for osteoarthritis: do patients actually wear them? Clinical orthopaedics and related research, 471(6), pp. 1982-1991.

33. BROUWER, R.W., JAKMA, T.S.C., VERHAGEN, A.P., VERHAAR, J.A.N. and BIERMA-ZEINSTRA, S., 2005. Braces and orthoses for treating osteoarthritis of the knee. The Cochrane Database Of Systematic Reviews, (1), pp. CD004020.

34. PAGANI, C.H., BOHLE, C., POTTHAST, W. And BRUGGEMANN, G.P., 2010. Short-term effects of a dedicated knee orthosis on knee adduction moment, pain, and function in patients with osteoarthritis. Archives of Physical Medicine and Rehabilitation, 91(12), pp. 1936-1941.

35. EBERT, J.R., HAMBLY, K., JOSS, B., ACKLAND, T.R. and DONNELLY, C.J., 2014. Does an unloader brace reduce knee loading in normally aligned knees? Clinical orthopaedics and related research, 472(3), pp. 915-922.

36. JONES, R.K., NESTER, C.J., RICHARDS, J.D., KIM, W.Y., JOHNSON, D.S., JARI, S., LAXTON, P. And TYSON, S.F., 2013. A comparison of the biomechanical effects of valgus knee braces and lateral wedged insoles in patients with knee osteoarthritis. Gait \& posture, 37(3), pp. 368-372.

37. KUTZNER, I., KUTHER, S., HEINLEIN, B., DYMKE, J., BENDER, A., HALDER, A.M. and BERGMANN, G., 2011. The effect of valgus braces on medial compartment load of the knee joint - in vivo load measurements in three subjects. Journal of Biomechanics, 44(7), pp. 1354-1360.

38. SELFE, J., RICHARDS, J., THEWLIS, D. And KILMURRAY, S., 2008. The biomechanics of step descent under different treatment modalities used in patellofemoral pain. Gait \& posture, 27(2), pp. 258-263.

39. SANCHEZ-RAMIREZ, D.C., MALFAIT, B., BAERT, I., VAN DER LEEDEN, M., VAN DIEEN, J., LEMS, W.F., DEKKER, J., LUYTEN, F.P., VERSCHUEREN, S., 2016. Biomechanical and neuromuscular adaptation during the landing phase of a stepping-down task in patients with early or established knee osteoarthritis. The Knee, 23 (3) 367-375.

40. CHILDS, J.D., SPARTO, P.J., FITSGERALD, G.K., BIZZINI, M., IRRGANG J.J. 2003. Alterations in lower extremity movement and muscle activation patterns in individuals with knee osteoarthritis. Clinical Biomechanics, 19 (1), 44-49.

41. ROOS, E.M., LOHMANDER, L. S., 2013. The Knee Injury and Osteoarthritis Outcome Score (KOOS): from joint injury to osteoarthritis. Health Qual Life Outcomes, 1: 64.

42. HANZLÍKOVÁ, I., RICHARDS, J., TOMSA M., CHOHAN, A., MAY, K., SMÉKAL, D., SELFE J., 2016. The effect of proprioceptive knee bracing on knee stability during three different sport related movement tasks in healthy subjects and the implications to the management of Anterior Cruciate Ligament (ACL) injuries. Gait Posture; 48:165-170.

43. DOSLIKOVA, K., 2015. Biomechanics of knee osteoarthritis during stair negotiation: mechanisms and intervention strategies. Thesis (Manchester Metropolitan University). 
Figure 1: Retroreflective marker set with the proprioceptive knee brace (OA Reaction, DJO, USA).

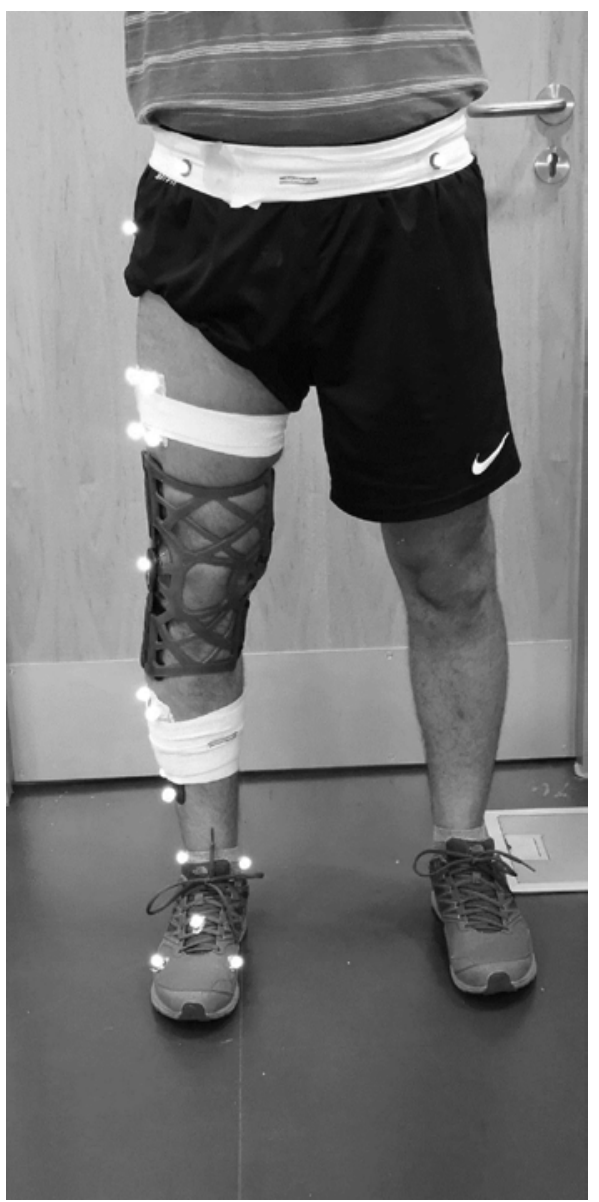


Table 1: Current International Guidelines on Orthotic Management of OA

\begin{tabular}{|l|c|c|c|}
\hline Guidance & Bracing & Sleeve & Insoles \\
\hline NICE & Adjunct & NA & Adjunct \\
\hline AAOS & Undecided & Undecided & Recommended \\
\hline ECR & Undecided & Undecided & Not recommended \\
\hline OARSI & NA & NA & Recommended \\
\hline SMOH & Recommended & Recommended & Recommended \\
\hline RACGP & Recommended & Recommended & Not recommended \\
\hline
\end{tabular}

National Institute for Health and Clinical Excellence (NICE) (NICE, 2014), American Association of Orthopaedic Surgeons (AAOS) (AAOS, 2013), American College of Rheumatology (ACR) (Hochberg et al., 2012), European League Against Rheumatism (Fernandes et al., 2013), The Royal Australian College of General Practitioners (RACGP) (RACGP, 2009), Singapore Ministry of Health (SMOH) (SMOH 2007), OA Research Society International (OARSI) (McAlindon et al., 2014a). 
Table 2: Angular Change (Min, Max, ROM) during step down

\begin{tabular}{|c|c|c|c|c|}
\hline & \multicolumn{3}{|c|}{ Healthy } \\
\hline & & $\begin{array}{c}\text { No brace } \\
\text { Mean (SD) }\end{array}$ & $\begin{array}{c}\text { Brace } \\
\text { Mean (SD) } \\
\end{array}$ & $\begin{array}{c}\text { Cls of the } \\
\text { differences }\end{array}$ \\
\hline \multirow{9}{*}{ Hip } & Sagittal Min & $-21.4(12.9)$ & $-20.0(14.1)$ & -3.5 to 0.8 \\
\hline & Coronal Min & $1.6(2.3)$ & $2.1(2.9)$ & -1.0 to 0.2 \\
\hline & Transverse Min & $-9.7(6.7)$ & $-10.6(6.8)$ & -0.5 to 2.3 \\
\hline & Sagittal Max & $-8.9(9.7)$ & $-8.4(11.3)$ & -2.3 to 1.2 \\
\hline & Coronal Max & $7.6(4.0)$ & $7.2(4.1)$ & -0.5 to 1.2 \\
\hline & Transverse Max & $-3.3(5.7)$ & $-4.2(6.5)$ & -0.5 to 2.2 \\
\hline & Sagittal ROM & $12.5(4.5)$ & $11.6(4.4)$ & 2.3 to -0.6 \\
\hline & Coronal ROM & $5.9(2.2)$ & $5.2(2.1)$ & 1.6 to -0.1 \\
\hline & Transverse ROM & $6.4(1.9)$ & $6.4(2.2)$ & 0.9 to -0.9 \\
\hline \multirow{9}{*}{ Knee } & Sagittal Min & $15.2(6.6)$ & $16.1(7.2)$ & -3.0 to 5.3 \\
\hline & Coronal Min & $-5.9(4.5)$ & $-5.7(3.9)$ & -1.3 to 1.2 \\
\hline & Transverse Min & $3.3(4.0)$ & $2.8(4.9)$ & -0.7 to 1.2 \\
\hline & Sagittal Max & $53.5(9.3)$ & $53.4(9.2)$ & -2.0 to 2.2 \\
\hline & Coronal Max & $-1.6(3.2)$ & $-1.9(2.9)$ & -0.4 to 1.0 \\
\hline & Transverse Max & $8.7(4.9)^{*}$ & $7.0(5.6)^{*}$ & 0.6 to 2.7 \\
\hline & Sagittal ROM & $38.3(7.0)$ & $37.3(6.2)$ & 2.8 to -0.7 \\
\hline & Coronal ROM & $4.3(2.2)$ & $3.8(2.1)$ & 1.7 to -0.8 \\
\hline & Transverse ROM & $5.4(2.4)^{*}$ & $4.2(1.9)$ * & 1.8 to 0.6 \\
\hline \multirow{9}{*}{ Ankle } & Sagittal Min & $-100.4(6.7)$ & $-100.4(7.2)$ & -0.7 to 0.7 \\
\hline & Coronal Min & $-15.5(7.2)^{*}$ & $-14.4(7.5)^{*}$ & -2.1 to 0.0 \\
\hline & Transverse Min & $-6.8(3.7)$ & $-6.5(3.7)$ & -0.9 to 0.3 \\
\hline & Sagittal Max & $-79.7(6.2)$ & $-80.3(5.9)$ & -0.0 to 1.2 \\
\hline & Coronal Max & $-6.6(6.8)$ & $-6.0(6.9)$ & -2.1 to 0.8 \\
\hline & Transverse Max & $-3.9(3.8)$ & $-3.9(3.4)$ & -0.4 to 0.5 \\
\hline & Sagittal ROM & $20.7(2.3)$ & $20.1(2.6)$ & 1.6 to -0.4 \\
\hline & Coronal ROM & $8.8(4.5)$ & $8.4(4.6)$ & 1.6 to -0.7 \\
\hline & Transverse ROM & $2.9(1.3)$ & $2.5(1.5)$ & 0.9 to -0.2 \\
\hline
\end{tabular}

* Significant difference between Brace and No Brace 
Table 3: Angular velocity (Min, Max, ROM) during step down

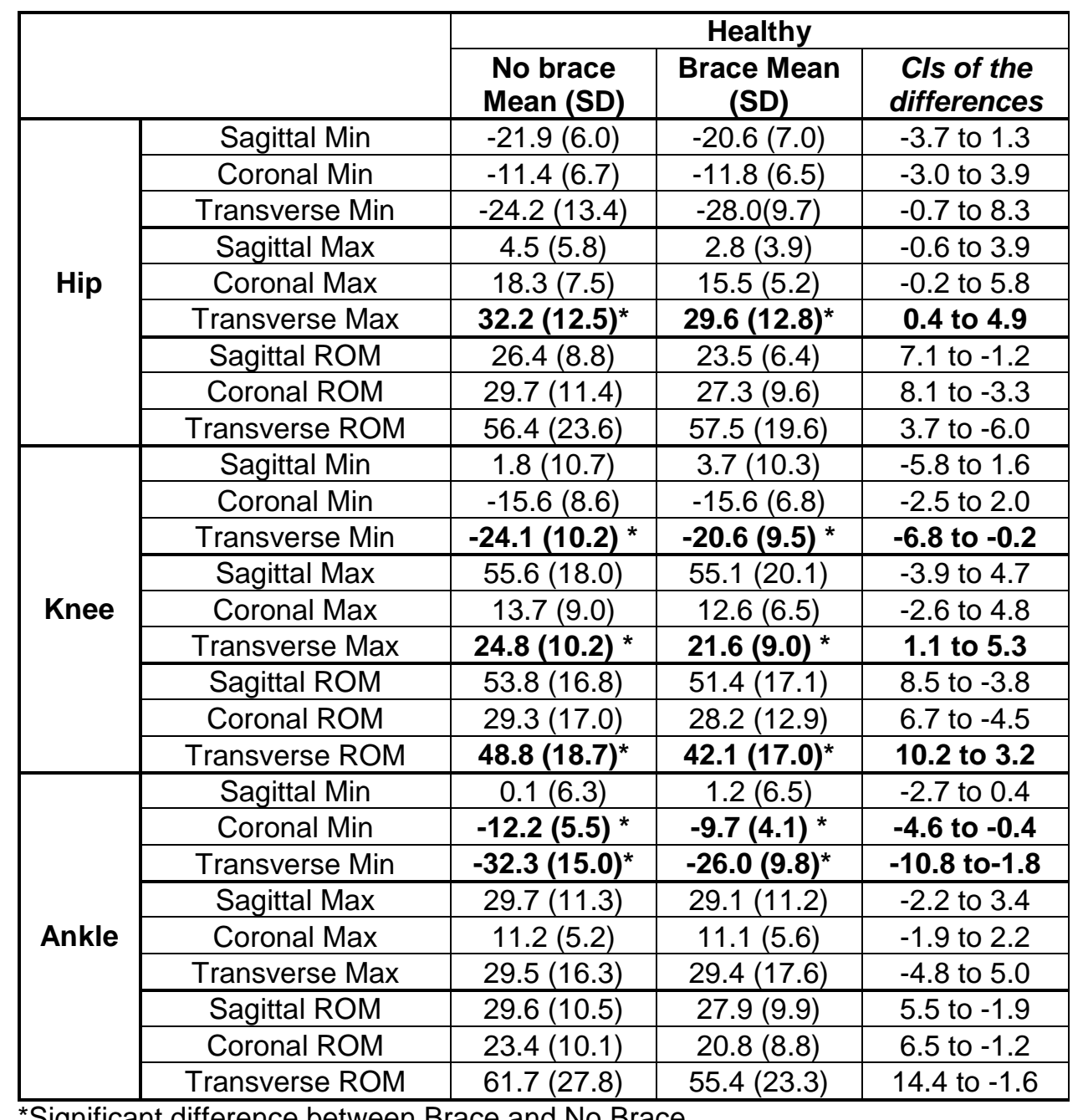

${ }^{*}$ Significant difference between Brace and No Brace 
Table 4: KOOS questionnaire results for participants with OA.

\begin{tabular}{|c|c|c|c|c|c|c|}
\hline \multicolumn{2}{|r|}{ Case } & Pain & Symptoms & $\begin{array}{l}\text { Activities of } \\
\text { Daily Living }\end{array}$ & $\begin{array}{c}\text { Sport/ } \\
\text { Recreation }\end{array}$ & $\begin{array}{l}\text { Quality of } \\
\text { Life }\end{array}$ \\
\hline \multirow[t]{2}{*}{$P 1$} & Pre & 55.6 & 71.4 & 67.6 & 35 & 25 \\
\hline & Post & 83.3 & 89.3 & 88.2 & 65 & 50 \\
\hline & \% Change & 50 & 25 & 30.4 & 85.7 & 100 \\
\hline \multirow[t]{4}{*}{$P 2$} & Pre & 27.8 & 32.1 & 29.4 & 5 & 12.5 \\
\hline & Post & 50 & 50 & 73.5 & 25 & 18.7 \\
\hline & \% Change & 80 & 55.5 & 149.9 & 400 & 50 \\
\hline & Pre & 41.7 & 46.4 & 60.3 & 25 & 18.7 \\
\hline \multirow[t]{3}{*}{ P3 } & Post & 94.4 & 89.3 & 98.5 & 95 & 62.5 \\
\hline & \% Change & 126.6 & 92.3 & 63.4 & 280 & 233.3 \\
\hline & $\begin{array}{c}\text { Average change } \\
(\%)\end{array}$ & $85.5 \%$ & $57.6 \%$ & $81.2 \%$ & $255.2 \%$ & $127.7 \%$ \\
\hline
\end{tabular}

